\title{
Thermal and Catalytic Fast Pyrolysis of Oily Extracts of Microalgae: Production of Biokerosene
}

\author{
Noyala S. C. Fonseca, ${ }^{a}$ Victor C. Oliveira, ${ }^{a}$ Roger Fréty ${ }^{\oplus a, b}$ and Emerson A. Sales ${ }^{\oplus *, a, c}$ \\ ${ }^{a}$ Laboratório de Bioenergia e Catálise (LABEC), Escola Politécnica, \\ Universidade Federal da Bahia (UFBA), Rua Aristides Novis, 2, $2^{\circ}$ andar, Federação, \\ 40210-630 Salvador-BA, Brazil \\ ${ }^{b}$ Departamento de Físico-Química, Instituto de Química, \\ Universidade Federal da Bahia (IQ-UFBA), Rua Barão de Geremoabo, $3^{\circ}$ andar, \\ Campus Universitário de Ondina, 40170-290 Salvador-BA, Brazil \\ 'Programa de Pós-Graduação em Engenharia Industrial (PEI), Escola Politécnica, \\ Universidade Federal da Bahia (UFBA), Rua Aristides Novis, 2, $6^{\circ}$ andar, Federação, \\ 40210-630 Salvador-BA, Brazil
}

\begin{abstract}
Three different microalgae species, Desmodesmus sp., Nannochloropsis oculata and Halamphora coffeaeformis were grown under controlled conditions. The resulting dry biomass was characterized by TG-DTA (thermogravimetry-differential thermal analysis) and extracted with three solvents having different polarities. The extracts gross mass yields varied from $2 \%$ using $n$-hexane to $23 \%$ (or $74 \%$ when subtracting the volatiles and ashes) when using methanolchloroform whatever the microalgae species. Fourier transform infrared (FTIR) spectra of all extracts suggested the presence of fatty esters and acids. The extracts were pyrolyzed at $600{ }^{\circ} \mathrm{C}$, using a micro pyrolizer coupled to a gas chromatograph-mass spectrometer (GC-MS), without and with $\gamma$-alumina as catalyst. Hydrocarbons concentrations varied respectively from $92 \%$ in the better case to $46 \%$ in the worst case. The $\mathrm{C} 9-\mathrm{C} 15$ fraction of these hydrocarbons, potentially useful for biokerosene formulation, was object of detailed analysis. In this fraction, nitrogenous products had concentrations always lower than $0.1 \%$. The main hydrocarbons produced were linear 1-alkenes for thermal pyrolysis whereas for pyrolysis with $\gamma$-alumina, linear 1 -alkenes and also alkenes isomers and linear alkanes, together with cyclic and aromatic compounds were observed for all microalgae species, but in different proportions. The C9-C15 fraction of pyrolyzed extracts can be considered as precursor for biokerosene or direct "drop in" fuel for kerosene petroleum fraction.
\end{abstract}

Keywords: microalgae, lipid extraction, flash pyrolysis, alumina catalyst, biokerosene

\section{Introduction}

Microalgae biomass is recognized as a promising source for several products for biorefineries. ${ }^{1-3}$ Fast pyrolysis and catalytic pyrolysis can promote deoxygenation of many compounds such as the fatty ones. ${ }^{4,5}$ Then, with oily species formed during microalgae growth, pyrolysis is theoretically able to generate hydrocarbons. Further, when pyrolysis of fatty compounds is performed at temperatures between 450 and $600{ }^{\circ} \mathrm{C}$, in a fast mode, it can simulate some chemical reactions occurring during a fluidized catalytic cracking (FCC) process, since the contact time between

*e-mail: eas@ufba.br the reagent and the catalyst is short and generally the catalyst/feed mass ratio is high. Attempts to co-process oxygenated fractions with traditional FCC feeds have been carried out in recent years and reviewed. ${ }^{6}$ Although some difficulty may appear, ${ }^{7}$ it was found that about 10 to $20 \%$ of oxygenated compounds can be added to a heavy oil charge, without altering significantly the final products yields and quality. ${ }^{8}$ So far, the oxygenated compounds tested in FCC coprocessing have been essentially triglyceride-based fractions and crude or upgraded bio-oil from agriculture's residues.

Despite their potential as alternative bio-fuel feeds, the oily compounds synthesized by microalgae are more complex to transform than other feedstocks like soybean 
or palm oil. Among the reasons for this complexity, can be cited a huge number of microalgae candidates, a rather low scale production, ${ }^{9}$ an oily products composition often depending on detailed culture conditions, ${ }^{10}$ a complex oily composition including very long chain and polyunsaturated fatty acids and amino-acids fractions. ${ }^{11}$ This latter part presents a high content in nitrogen, element known as detrimental for both the bio-fuel quality and the catalysts performance. ${ }^{12}$

Various routes can be considered for transforming microalgae oily compounds into fuels, using directly the biomass, in water suspension or after drying, or performing the extraction of the oily compounds followed by transformation to fuels. These transformations can then be purely thermal or assisted by catalysts, and in the latter case, cracking or hydrotreatment-like conditions can be used. Some works using microalgae as starting materials and thermal processes to obtain biofuels or "drop in" fractions are summarized right after.

Bach and $\mathrm{Chen}^{13}$ reviewed the pyrolysis of different microalgae at moderate temperatures $\left(400-600{ }^{\circ} \mathrm{C}\right)$ in an inert atmosphere through thermogravimetric analysis; kinetic models were applied for kinetic evaluation and pyrolysis parameters estimation. Choo et al. ${ }^{14}$ analyzed in a recent review the progresses in catalytic conversion of microalgae to green hydrocarbons. Although some positive results are described, the authors concluded that understanding of fundamental chemistry and mechanisms involved in catalytic deoxygenation is crucial for further developments. Li et al.,${ }^{15}$ in another review of catalytic pyrolysis of microalgae, stated that $\mathrm{Ni}$ and Pd supported on zeolites are suitable for hydrodeoxygenation and partially efficient for denitrogenation. These authors also concluded that further research is still required to improve the quality of bio-oil from fast and catalytic pyrolysis of microalgae.

Maguyon and Capareda ${ }^{16}$ transformed Nannochloropsis oculata during pressurized pyrolysis. They obtained a bio-oil with a high heating value (HHV) of $38 \mathrm{MJ} \mathrm{kg}^{-1}$, the bio-oil containing 35 and $34 \%$ of saturated and unsaturated aliphatics, respectively, and $14 \%$ aromatics, the products having a chain length ranging from C8 to C21. Gong et al. ${ }^{17}$ studied the decomposition of Chlorella vulgaris and Dunaliella salina, two low lipid microalgae. Pyrolysis experiments were carried out both on a fixed-bed reactor and by thermogravimetry. The microalgae pyrolytic oil was found to have significant levels of alkanes, alkenes, alkynes, and esters and was particularly rich in nitrogenous compounds. By comparison with bio-oils from lignocellulosic biomass, the microalgae oil had lower oxygen and water contents, lower total acid number, and higher heating value. Silva and Monteggia ${ }^{18}$ studied the production of algal biomass obtained from algae ponds treating sewage and the pyrolysis of the dry biomass obtained after flocculation and sedimentation. The thermal tests were carried out in an inert nitrogen atmosphere at 400 , 500 and $600{ }^{\circ} \mathrm{C}$. The results showed that the liquid pyrolysis product amount (bio-oil + water) was maximum at $450^{\circ} \mathrm{C}$. Gang et al. ${ }^{19}$ studied the pyrolysis of Desmodesmus sp. cultivated in anaerobic digested effluents, between 300 and $800{ }^{\circ} \mathrm{C}$. The authors concluded that a pyrolysis temperature of $600{ }^{\circ} \mathrm{C}$ was optimum for production of biofuel. In another study with Desmodesmus sp. cultivated in BG11 medium, Gang et al. ${ }^{20}$ concluded that $700{ }^{\circ} \mathrm{C}$ was an optimum temperature for pyrolysis, because higher temperatures generated polluting products based on nitrogen containing molecules and polycyclic aromatics. In a third work, Gang et al. ${ }^{21}$ finally stated that the optimum temperature for Desmodesmus sp. cracking was $650{ }^{\circ} \mathrm{C}$ with a $32 \%$ of bio-oil production yield. Pinho et al..$^{22}$ studied Chlorella vulgaris and Arthrospira platensis showing high heating value and low ash content. Through pyrolysis experiments, they found toluene, styrene and phenol products and suggested that both microalgae have potential for biofuels and biochemicals. Wang et al. ${ }^{23}$ studied Micractinium conductrix microalga growth and showed that harvesting during the final part of exponential growth led to the highest aliphatics and lowest nitrogenated products amounts after pyrolysis at $550{ }^{\circ} \mathrm{C}$.

Thangalazhy-Gopakumar et al. ${ }^{24}$ pyrolyzed Chlorella vulgaris in a fixed bed reactor and produced around $53 \%$ of bio-oil. In the presence of HZSM-5 catalyst, they obtained up to $26 \%$ of aromatics when increasing the mass ratio catalyst/biomass from 0 to 9 . Torri et al. ${ }^{25}$ obtained bio-oil from Desmodesmus sp. via hydrothermal treatment (HTT). This bio-oil was further pyrolyzed at $600{ }^{\circ} \mathrm{C}$ in the presence of HZSM- 5 catalyst. They observed that nitrogen removal was remarkably high and concluded that HTT bio-oil could be introduced in existing refineries. Wang and Brown ${ }^{26}$ studied a promising microalgae biorefinery pathway, performing catalytic pyrolysis with HZSM-5 catalyst to convert the whole microalgae biomass into aromatic hydrocarbons, using Chlorella vulgaris, at various reaction temperatures and catalyst loads. The results demonstrated that catalytic pyrolysis of microalgae produces better aromatic yields and more monocyclic aromatics than catalytic pyrolysis of red oak. Du et al. ${ }^{27}$ used H-Y, H-Beta and HZSM-5 to study the effect of catalyst type on the aromatic yield during pyrolysis of microalgae and egg whites and compared their results with non-catalytic experiments. HZSM-5 was the most effective catalyst giving an 
aromatic yield of $18.13 \%$. They also studied the effect of $\mathrm{Si} / \mathrm{Al}$ ratio in HZSM-5 on the aromatic yield. The maximum production of aromatics was achieved at the $\mathrm{Si} / \mathrm{Al}$ ratio of 80 , implying moderate acidity of the catalyst and a reduced coke formation. Aromatic production was also increased with the incorporation of copper or gallium to HZSM-5. Aysu and Sanna ${ }^{28}$ studied Nannochloropsis pyrolysis over different Ni-Ce based catalysts; in the best conditions, they obtained $23 \%$ mass yield of a bio-oil yield with a low content of residual acids and a high content of aliphatics. Conti et al. ${ }^{29}$ studied the catalytic pyrolysis of Desmodesmus communis. Using HZSM-5 they showed that denitrogenation and deoxygenation increased by increasing the zeolite load from 1:5 to 1:20. Also using HZSM-5, Anand et al. ${ }^{30}$ performed pyrolyzes in an analytical pyrolyzer coupled with gas chromatographmass spectrometer (GC-MS). Long chain carboxylic acids, such as tetradecanoic and hexadecanoic acids, were observed as the major products between $350-650{ }^{\circ} \mathrm{C}$ in the absence of catalyst. Catalytic fast pyrolysis was performed at $400{ }^{\circ} \mathrm{C}$ using hydrogen-zeolite $\mathrm{Y}(\mathrm{ZYH})$, sodium-zeolite $\mathrm{Y}(\mathrm{ZYNa})$, and oxides like $\mathrm{MgO}, \mathrm{ZrO}_{2}$ and $\mathrm{TiO}_{2}$. Polyaromatic hydrocarbons and nitriles amounts increased, while the formation of long chain carboxylic acids decreased with increasing acidity of ZY. Formation of symmetrical long chain ketones was observed at $400{ }^{\circ} \mathrm{C}$ with $\mathrm{ZYNa}, \mathrm{MgO}$ and $\mathrm{ZrO}_{2}$ catalysts. With $\mathrm{TiO}_{2}$ as catalyst, the number of compounds containing nitrogen was increased. The authors concluded that production of valuable chemical intermediates can be achieved from complex feedstocks like microalgae via catalytic fast pyrolysis using zeolites and metal oxides. Ren et al. ${ }^{31}$ studied the bio-oil obtained from hydro liquefaction of Botryococcus braunii microalgae. The bio-oil was both catalytically cracked and hydrotreated. The cracking led essentially to aromatics whereas hydrotreating allowed formation of straight and branched aliphatics. They also observed that catalytic cracking displayed better ability for oxygen removal. Chang et al. ${ }^{32}$ performed pyrolysis of Nannochloropsis sp. alone or mixed with palm kernel shell at $600{ }^{\circ} \mathrm{C}$. They found a synergistic effect during co-pyrolysis for aromatics formation. The pyrolysis over $\mathrm{Cu}-\mathrm{HZSM}-5$ catalyst further increased the aromatics yield. Zainan et $a l .{ }^{33}$ performed catalytic pyrolysis of Chlorella vulgaris using $\mathrm{Ni}$ supported zeolite catalysts, changing both pyrolysis temperature and catalyst/algal mass ratio. They obtained bio-oil rich in deoxygenated and denitrogenated hydrocarbons and with low acidity. Shimada et al. ${ }^{34}$ studied the catalytic cracking of Euglena gracilis extracted wax esters. Using equilibrium fluid cracking catalyst at $470{ }^{\circ} \mathrm{C}$, they showed that a high amount of paraffins and olefins and a low quantity of polyaromatics was obtained when pyrolyzing wax esters extracts by comparison with triglyceride pyrolysis. Fréty et al. ${ }^{35}$ observed that since 2011 industrial processes for cracking and hydrocracking of triglycerides of vegetable origin have been used to produce renewable liquid fuels. Cruz et al. ${ }^{36}$ hydrocracked a bio-oil extracted from Monoraphidium sp. between 300 and $350{ }^{\circ} \mathrm{C}$, under high hydrogen pressure in contact with Ru/alumina catalyst. With an $n$-hexane extract feedstock, catalytic hydrocracking led to $80 \%$ hydrocarbon mass yield.

All these studies show that $(i)$ rather different results, even within same groups, have been presented, (ii) detailed analysis of pyrolysis products are scarcely given and sometimes suffer from confusing identification, ${ }^{28}$ (iii) a limited number of works are related to lipids extracts from microalgae, and using catalysts limiting the amount of aromatics production. The results, however, confirmed that pyrolysis between 450 and $650{ }^{\circ} \mathrm{C}$, in absence of added hydrogen and in the presence of large amounts of catalysts, i.e., in experimental conditions close to that used in FCC process, can be an excellent way to obtain bio-fuel strongly deoxygenated and partially denitrogenated, starting with a lipidic feed issued from microalgae.

In the present work, microextractions ${ }^{37}$ and fast catalytic micro-pyrolysis were used for preparation and transformation of microalgal biomass, aiming at the production of compounds compatible with kerosene. The feed derived from microalgal biomass was composed of oily compounds produced by three different species, Desmodesmus sp., Nannochloropsis oculata and Halamphora coffeaeformis. Chemical extraction was performed by using three different solvents, and the extracts were pyrolyzed in absence or presence of $\gamma$-alumina as catalyst, as alumina is known to present good deoxygenation properties with traditional triglycerides and derived compounds. ${ }^{38-41}$

\section{Experimental}

Cultivation was done in $1 \mathrm{~L}$ conical flasks in a phototrophic batch, with cultivation media that try to reproduce the nutrients needed for the species to develop under conditions similar to those found in the nature. The Nannochloropsis oculata and Halamphora coffeaeformis species are marine microalgae, so modified Conway medium $^{42}$ was used with seawater collected in the open sea. The Desmodesmus sp. species, being natural from freshwater, was cultivated using Bold's basal medium $(\mathrm{BBM}),{ }^{43}$ with distilled water. The general conditions of the cultivations performed are listed in Table 1 . 
Table 1. General conditions of microalgae cultivation

\begin{tabular}{|c|c|c|c|}
\hline \multirow{2}{*}{ Parameter } & \multicolumn{3}{|c|}{ Species } \\
\hline & Desmodesmus sp. & Nannochloropsis oculata & Halamphora coffeaeformis \\
\hline Brightness / $\left(\mu \mathrm{mol} \text { photons } \mathrm{m}^{-2} \mathrm{~s}^{-1}\right)^{\mathrm{a}}$ & 75 & 75 & $50^{\mathrm{b}}$ \\
\hline Shaking / rpm & no & no & 120 \\
\hline Temperature $/{ }^{\circ} \mathrm{C}$ & 25 & 25 & 35 \\
\hline Volume of cultivation / L & 1 & 1 & 0.75 \\
\hline Cultivation time / days & 40 & 20 & 32 \\
\hline Cultivation medium & Bold's basal medium (BBM) & Conway & Conway with sodium silicate \\
\hline $\mathrm{pH}$ & $6.6-7$ & 8.5 & 8.5 \\
\hline
\end{tabular}

${ }^{\mathrm{a} C o n v e r s i o n: ~} 1 \mu \mathrm{mol}$ photons $\mathrm{m}^{-2} \mathrm{~s}^{-1}=74$ lux (lx) (cool white fluorescent lamp); ${ }^{\mathrm{b}}$ photoperiod: $12 / 12 \mathrm{~h}$.

The catalyst used in the present work was a $\gamma$-alumina (Alcoa Alumínio S.A., Poços de Caldas, MG, Brazil, code: A $1,0.013 \%$ silica and $0.48 \%$ sodium, Brunauer-EmmettTeller (BET) surface area $71 \mathrm{~m}^{2} \mathrm{~g}^{-1}$ ).

\section{Thermogravimetric analyses of biomass}

Thermogravimetric analyses (TGA) were done to determine the amounts of highly volatile material (including moisture), mild volatile material (volatiles) and ash content. These analyses were carried out on a DTG-60/60H thermo-balance (Shimadzu, Kyoto, Japan), with sensitivity of $0.1 \mu \mathrm{g}$, using algae sample mass of approximately $2 \mathrm{mg}$, platinum sample holder and heating rate of $20{ }^{\circ} \mathrm{C} \mathrm{min}^{-1}$. Thermograms were obtained under synthetic air flow of $10 \mathrm{~mL} \mathrm{~min}^{-1}$, between 20 and $650{ }^{\circ} \mathrm{C}$.

\section{Extraction procedure}

The culture was centrifuged (4200 rpm for $10 \mathrm{~min}$ ) for collection of the cells, and the supernatant solution discarded. The resulting wet biomass was dispersed in Petri plates which remained in an aerated oven at $60{ }^{\circ} \mathrm{C}$ for $24 \mathrm{~h}$ for drying and subsequent use. To obtain the extracts, the procedure was different, as outlined in Figure 1. After centrifugation, $0.2 \mathrm{~g}$ of the semi-dried biomass (only two hours at $\left.60{ }^{\circ} \mathrm{C}\right)$ was frozen $\left(-4{ }^{\circ} \mathrm{C}\right)$ and manually ground for microextraction.

The extraction reagents were: (i) $n$-hexane $(97 \% \mathrm{v} / \mathrm{v}$ purity), (ii) isopropanol ( $99.5 \% \mathrm{v} / \mathrm{v}$ purity), (iii) chloroform (99\% v/v purity) and (iv) methanol (99.8\% v/v purity), all from Sigma-Aldrich (St. Louis, USA). Three solvents were used: pure hexane; hexane-isopropanol in the ratio 3:2 (v/v); and chloroform-methanol in the ratio 3:2(v/v). Each of the three microalgae species was extracted with each one of these three solvents, resulting in nine experiments. These extracts were dried under nitrogen gas

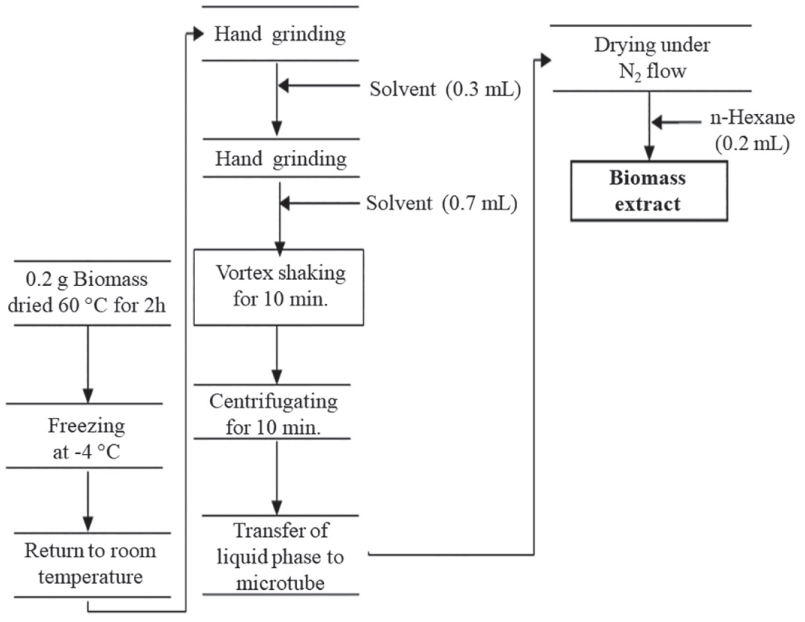

Figure 1. Flow chart for the extraction method.

flow, resuspended with $0.2 \mathrm{~mL}$ of $n$-hexane and an aliquot was used for pyrolysis.

The extraction percent mass yield was calculated as follows:

Yield $^{\mathrm{A}}(\%)=($ mass of extract $(\mathrm{g}) /$ total biomass $(\mathrm{g})) \times$

100

Yield $^{\mathrm{B}}(\%)=($ mass of extract $(\mathrm{g}) /($ total biomass -

(ash mass) $-($ volatile mass $)(\mathrm{g}))) \times 100$

where the volatile mass is the mass lost up to $200{ }^{\circ} \mathrm{C}$, that means, moisture + highly volatile compounds as measured by TG experiments.

\section{Fourier transform infrared (FTIR) spectroscopy of extracts}

The dry extracts, after mixing with $\mathrm{KBr}$ and pelletizing, were analyzed by infrared spectroscopy. The resulting disks were analyzed by FTIR at room temperature $\left(23^{\circ} \mathrm{C}\right)$, under ambient atmosphere using a Bomen spectrophotometer model MB 102. 


\section{Pyrolysis and product analysis}

Pyrolysis reactions were done using a Frontier Laboratories Ltd. Multi-Shot Pyrolyzer Model EGA/ PY-3030D connected online with a gas chromatograph coupled to mass spectrometer (Agilent GC-MS 5799A). A Frontier Laboratories UA5-30M-0.25F GC column was used (30 m length, $0.25 \mathrm{~mm}$ diameter, $5 \%$ diphenyl stationary phase and $95 \%$ dimethylpolysiloxane, $0.25 \mu \mathrm{m}$ film thickness), subjected to an initial temperature of $40{ }^{\circ} \mathrm{C}$ for $2 \mathrm{~min}$, followed by a heating ramp at a rate of $20{ }^{\circ} \mathrm{C} \mathrm{min}{ }^{-1}$ up to $320^{\circ} \mathrm{C}$, temperature maintained for more $10 \mathrm{~min}$. The MS ion source and the interface pyrolyzer/ injector temperatures were both fixed at $320{ }^{\circ} \mathrm{C}$. Values of $\mathrm{m} / \mathrm{z}$ were set in the range of 40 to 400 , in scan mode. The split ratio used was $1 / 50$, the helium flow in the column

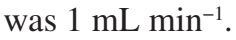

After solubilization of the dried extract in $n$-hexane, $1 \mu \mathrm{L}$ of the solution was dropped onto $0.002 \mathrm{~g}$ of alumina catalyst in powder form disposed at the bottom of a deactivated stainless-steel sample holder (Eco-cup LF PY1-EC80F, Frontier Laboratories), and the mixture was subsequently covered by a tiny layer of quartz wool. The sample holder was then placed in the equipment under helium flow for purging, and the micro-pyrolyzer furnace was preheated to the desired pyrolysis temperature $\left(600^{\circ} \mathrm{C}\right)$. After stabilization, the sample holder was dropped into the hot zone where it remained for $15 \mathrm{~s}$ at the chosen temperature. An aliquot of the gas phase was automatically inserted into the GC-MS equipment.

For the analysis of the products, the chromatographic peaks with area lower than $0.1 \%$ of the total area were neglected. The peaks were identified using the NIST Database, and only those products with identification probability greater than $70 \%$ were considered. Products presenting an incoherent identification in terms of logic in the appearance sequence, and those with a probability of identification below $70 \%$, were grouped as not identified (NI). The estimated compositions after pyrolysis were calculated dividing the peak areas of the specific products by the total area of the non-neglected peaks, including the non-identified products.

\section{Results and Discussion}

Microalgae biomass thermogravimetric analyses

The thermogravimetric analyses showed that the three microalgae of this study have qualitatively limited differences in behavior (Figures $2 \mathrm{a}, 2 \mathrm{~b}$ and $2 \mathrm{c}$ ).

Table 2 summarized the main mass losses obtained, in
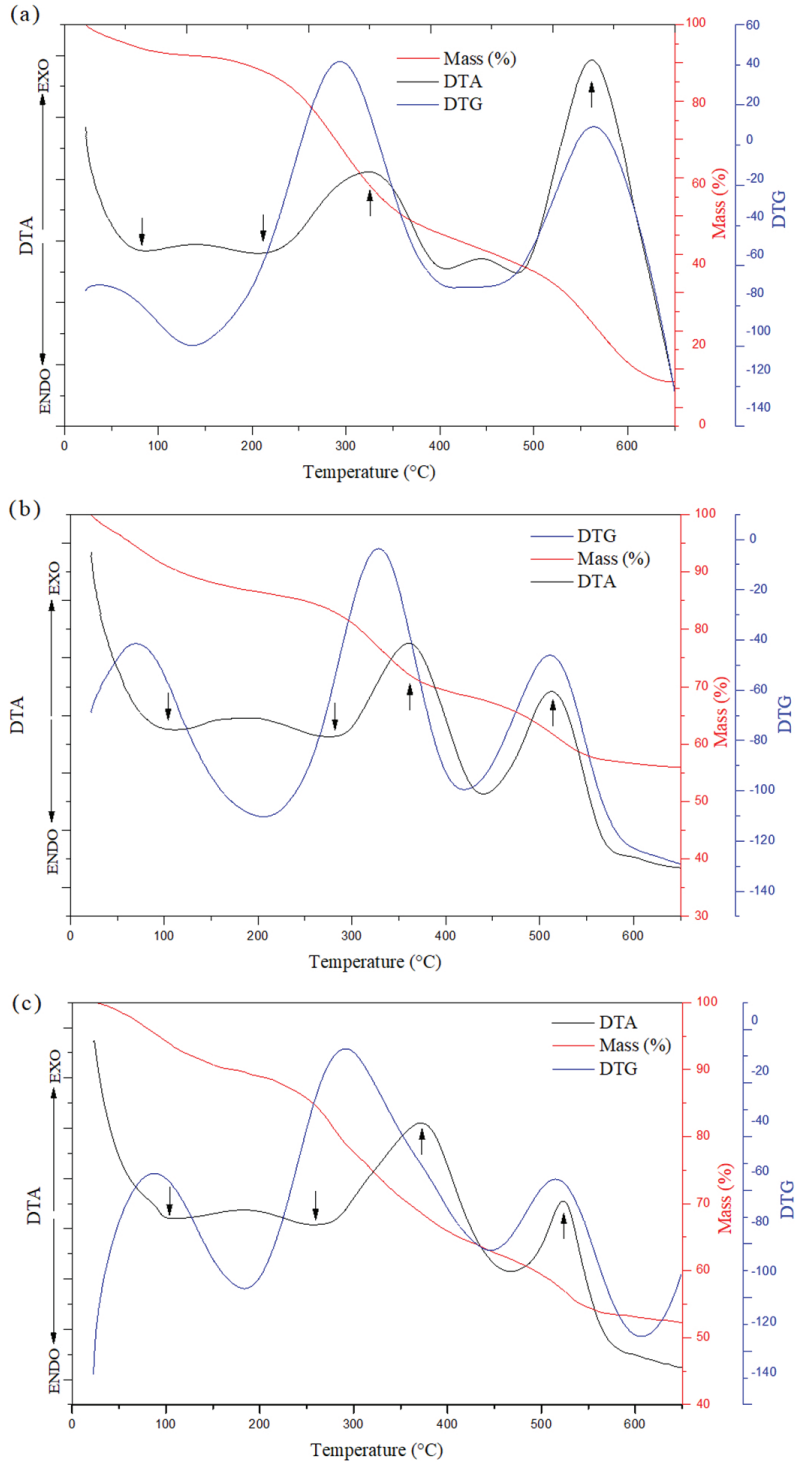

Figure 2. Biomass DTA (differential thermal analysis), DTG (derivative thermogravimetry) and TGA (thermogravimetric analysis), under synthetic air flow of: (a) Desmodesmus sp.; (b) Nannochloropsis oculata; (c) Halamphora coffeaeformis. The internal arrows in the case of DTA curve are indicating the main places where thermal phenomena were considered (downward arrows for endotherms, upward arrows for exotherms).

percentage for each event, for the three microalgae species studied.

Three main events of mass loss are seen whatever the microalgae species studied. The first event, endothermic, which ended between 150 to $200{ }^{\circ} \mathrm{C}$ may be mainly related to the elimination of residual water and possibly light organic compounds. The second mass loss event seen between approximately 200 and $450{ }^{\circ} \mathrm{C}$ starts with an endothermal signal followed by an important exothermal one: it is attributed to a complex situation implying at least two kinds of reactions since the DTA (differential thermal analysis) profile is not strictly synchronized with the 
Table 2. Water (I), volatiles (II + III) and ash content of microalgal biomasses

\begin{tabular}{lcccccc}
\hline Biomass & $\begin{array}{c}\text { Initial mass / } \\
\mathrm{mg}\end{array}$ & $\begin{array}{c}\text { Final mass } \\
(\mathrm{ash}) / \mathrm{mg}\end{array}$ & Ash / $\%$ & $\begin{array}{c}\text { Event I } \\
\left.\text { (up to } 200{ }^{\circ} \mathrm{C}\right) / \%\end{array}$ & $\begin{array}{c}\text { Event II } \\
\left(200-450{ }^{\circ} \mathrm{C}\right) / \%\end{array}$ & $\begin{array}{c}\text { Event III } \\
\left(\text { above } 450{ }^{\circ} \mathrm{C}\right) / \%\end{array}$ \\
\hline Desmodesmus sp. & 2.22 & 0.24 & 11.10 & 7.70 & 47.80 & 33.40 \\
Nannochloropsis oculata & 2.39 & 1.33 & 55.94 & 13.50 & 19.20 & 11.36 \\
Halamphora coffeaeformis & 2.05 & 1.07 & 52.22 & 9.00 & 27.50 & 11.28 \\
\hline
\end{tabular}

differential mass loss (DTG, derivative thermogravimetry). This second event can be the result of the contribution of endothermic processes linked to the volatilization of middle weight organic compounds and exothermic oxidation reactions and/or auto-oxidation of some species. The third mass loss event, above $450{ }^{\circ} \mathrm{C}$, in which DTA (exothermic phenomenon) and DTG profiles are occurring with good synchronism may be related to the combustion of heavy organic compounds, together with carbon residues formed during the second event.

Thermograms showing the same type of behavior have been observed by Chen et al. ${ }^{44}$ when performing thermogravimetry in oxidizing atmosphere of Chlorella vulgaris. They suggested that the low temperature event is linked to dehydration and that the second and third events are associated with oxidation. Agrawal and Chakraborty ${ }^{45}$ also investigated the degradation of Chlorella vulgaris: they verified the presence of three steps of mass loss and attributed the events to the phenomena mentioned above. However, they suggested that during the second event there is a contribution of the devolatilization and combustion events of proteins and carbohydrates, the combustion of lipids being mainly linked with the high temperature event. They determined activation energies of $45 \mathrm{~kJ} \mathrm{~mol}^{-1}$ for protein and carbohydrate transformation, and $63 \mathrm{~kJ} \mathrm{~mol}^{-1}$ for lipid decomposition. The present results are therefore in good agreement with preceding results obtained using other microalgae species.

The high ash content of Nannochloropsis oculata and Halamphora coffeaeformis (Table 2) may be associated with the fact that these microalgae species were cultivated in sea water, with salt concentrations very much higher than that used for cultivation of Desmodesmus sp. In the case of Halamphora coffeaeformis it is worth to mention that this species has a silica skeleton also responsible for higher mineral content. However, when comparing the thermal analyses of the three microalgae (Figure 2), it also appears that the weight loss of Nannochloropsis oculata and Halamphora coffeaeformis stabilizes at lower temperatures than that for Desmodesmus species. This last observation suggests that some minerals present in the ashes may act as combustion catalysts, helping the organic material to be more quickly eliminated, as observed with lignocellulosic biomass, ${ }^{46}$ as well as with microalgae biomass ${ }^{47}$ for both combustion and pyrolysis processes.

\section{FTIR spectroscopic analyses of the extracts}

FTIR spectra of all extracts were very similar. Figure 3 shows the spectrum of the extract of Nannochloropsis oculata obtained using $n$-hexane as solvent, considered as representative of the other extracts. Although the extracts contain substances with different chemical functions, some characteristic bands were always present. The most intense absorption bands were due to the $\mathrm{C}=\mathrm{O}$ stretching vibration of the ester carbonyl group at $1747 \mathrm{~cm}^{-1}$ with a discrete shoulder in the same region, at about $1727 \mathrm{~cm}^{-1}$, suggesting the presence of free acids in the extract. The asymmetric and symmetric stretching bands of the $\mathrm{C}-\mathrm{H}$ bond in $\mathrm{CH}_{2}$ and $\mathrm{CH}_{3}$ groups were observed at 2924 and $2852 \mathrm{~cm}^{-1}$, respectively, suggesting the presence of long carbon chains, such those present in fatty esters and acids. In the region between 1400 and $1500 \mathrm{~cm}^{-1}$, poorly resolved bands attributed to symmetric angular deformation in the plane of $\mathrm{CH}_{2}\left(\delta_{\mathrm{s}}\left(\mathrm{CH}_{2}\right)\right)$ and asymmetric deformation of $\mathrm{CH}_{3}\left(\delta_{\text {as }}\left(\mathrm{CH}_{3}\right)\right)$ appear, reinforcing the presence of these functional groups. At approximately $1160 \mathrm{~cm}^{-1}$, a broad band is observed, whose origin refers to the asymmetric stretch of C-O-C ester bond; another important band is the one located near $1120-1090 \mathrm{~cm}^{-1}$, relative to the

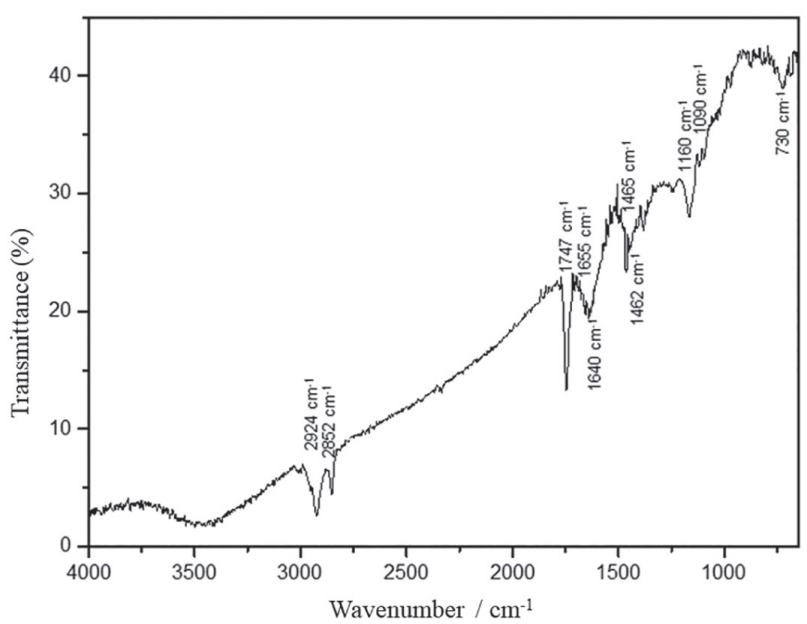

Figure 3. Infrared $(\mathrm{KBr})$ spectrum of the $n$-hexane extract of Nannochloropsis oculata. 
stretching of the uncoupled $\mathrm{C}-\mathrm{O}$ bond of esters. A band of low intensity at $730 \mathrm{~cm}^{-1}$ refers to the asymmetric angular deformation mode in the plane $\left(\rho\left(\mathrm{CH}_{2}\right)\right)$. Finally, two bands in the region $1600-1700 \mathrm{~cm}^{-1}$ were attributed to $\mathrm{C}-\mathrm{C}$ and $\mathrm{C}=\mathrm{C}$ stretching vibrations. All these bands were observed in all the extracts.

Table 3 shows the masses obtained after final drying under $\mathrm{N}_{2}$ flow, with the respective yields of extracts for each solvent used, for the three microalgae species studied.

With increasing solvent polarity, the mass of the extracts increased, result consistent with the probability of the solvent interacting more strongly with wider classes of bio-compounds such as proteins and carbohydrates as previously observed by Stepan et al. ${ }^{48}$ when extracting moist microalgae for biokerosene production. The intensification of colors when using solvent with high polarity confirmed the extraction of more material. However, the increase in mass yield does not simply reflect a greater extraction of fatty compounds such as fatty acids, fatty esters and triglycerides, but also of proteins, carbohydrates and pigments. After correction of ash and high volatile compounds (including moisture), the marine species Nannochloropsis oculata and Halamphora coffeaeformis presented much higher extraction yield values than Desmodesmus sp., as expected, due to the higher concentration of minerals in their biomasses.

\section{Fast pyrolysis of extracts}

It was first verified that after dropping the extracts on the alumina surface, solvent residues do not interfere in a significant way to pyrograms. The contribution of solvent residue areas to the whole pyrograms was always lower than $1 \%$ of the total area and was therefore neglected.
A reference pyrogram obtained during the uncatalyzed pyrolysis at $600^{\circ} \mathrm{C}$ was established for comparison with the results of catalyzed pyrolysis. Figure 4 presents a fraction of pyrograms of the $n$-hexane extracts of Desmodesmus sp. with and without $\gamma$-alumina as catalyst.

When performing pyrolysis in presence of $\gamma$-alumina catalyst, aiming at cracking and deoxygenation of the feed to a greater degree, the number of products increases significantly (Figure 4a). Unsaturated hydrocarbons are predominant, but saturated hydrocarbons are favored by the catalytic process. The hexadecanoic acid, which is found in a considerable amount after the non-catalytic pyrolysis, and also probably present in the original extract, was detected in a very low quantity after catalytic pyrolysis. The long chain alcohol (compound 12), present in great amount in both thermal and catalytic pyrolysis does not have a great probability to resist the high pyrolysis temperature used in the present work, as alcohols are known to easily dehydrate at rather low temperatures. ${ }^{49}$ The alcohol presence is therefore attributed to a possible hydration of alkenes formed during pyrolysis with water traces, the reaction occurring during the transfer of products from the pyrolysis area at $600^{\circ} \mathrm{C}$ to the analytical equipment, in which the interface temperature was kept at $320{ }^{\circ} \mathrm{C}$. Fatty alcohols are, however, often considered as intermediate products during pyrolysis of fatty acids, like other oxygenated products such as ketones and aldehydes. ${ }^{41,50,51}$

The products obtained from the catalytic pyrolysis are shown in the pyrograms of Figure 5, for three extracts of Nannochloropsis oculata microalgae. Similar profiles were obtained with the other microalgae species, using the same solvents. Although the extraction allowed a simplification of the feed for pyrolysis, doing a selection and concentration of some microalgae compounds, the extracted mixtures

Table 3. Mass yield of extractions

\begin{tabular}{|c|c|c|c|c|c|}
\hline \multirow{2}{*}{ Species } & \multirow{2}{*}{ Solvent } & \multirow{2}{*}{ Biomass / g } & \multirow{2}{*}{ Extract / g } & \multicolumn{2}{|c|}{ Mass yield / \% } \\
\hline & & & & A & B \\
\hline \multirow{3}{*}{ Desmodesmus sp. } & (1) hexane & 0.2047 & 0.0044 & 2.2 & 2.6 \\
\hline & (2) hexane + isopropanol & 0.2021 & 0.0068 & 3.4 & 4.1 \\
\hline & (3) chloroform + methanol & 0.2040 & 0.0467 & 22.9 & 28.2 \\
\hline \multirow{3}{*}{ Nannochloropsis oculata } & (1) hexane & 0.2008 & 0.0047 & 2.3 & 7.7 \\
\hline & (2) hexane + isopropanol & 0.2002 & 0.0121 & 6.0 & 19.8 \\
\hline & (3) chloroform + methanol & 0.2010 & 0.0459 & 22.8 & 74.8 \\
\hline \multirow{3}{*}{ Halamphora coffeaeformis } & (1) hexane & 0.2010 & 0.0075 & 3.7 & 9.6 \\
\hline & (2) hexane + isopropanol & 0.2012 & 0.0140 & 7.0 & 17.9 \\
\hline & (3) chloroform + methanol & 0.2019 & 0.0460 & 22.8 & 58.7 \\
\hline
\end{tabular}

A: using total biomass; B: using biomass amount corrected from ash and highly volatile compounds (see Experimental section). 


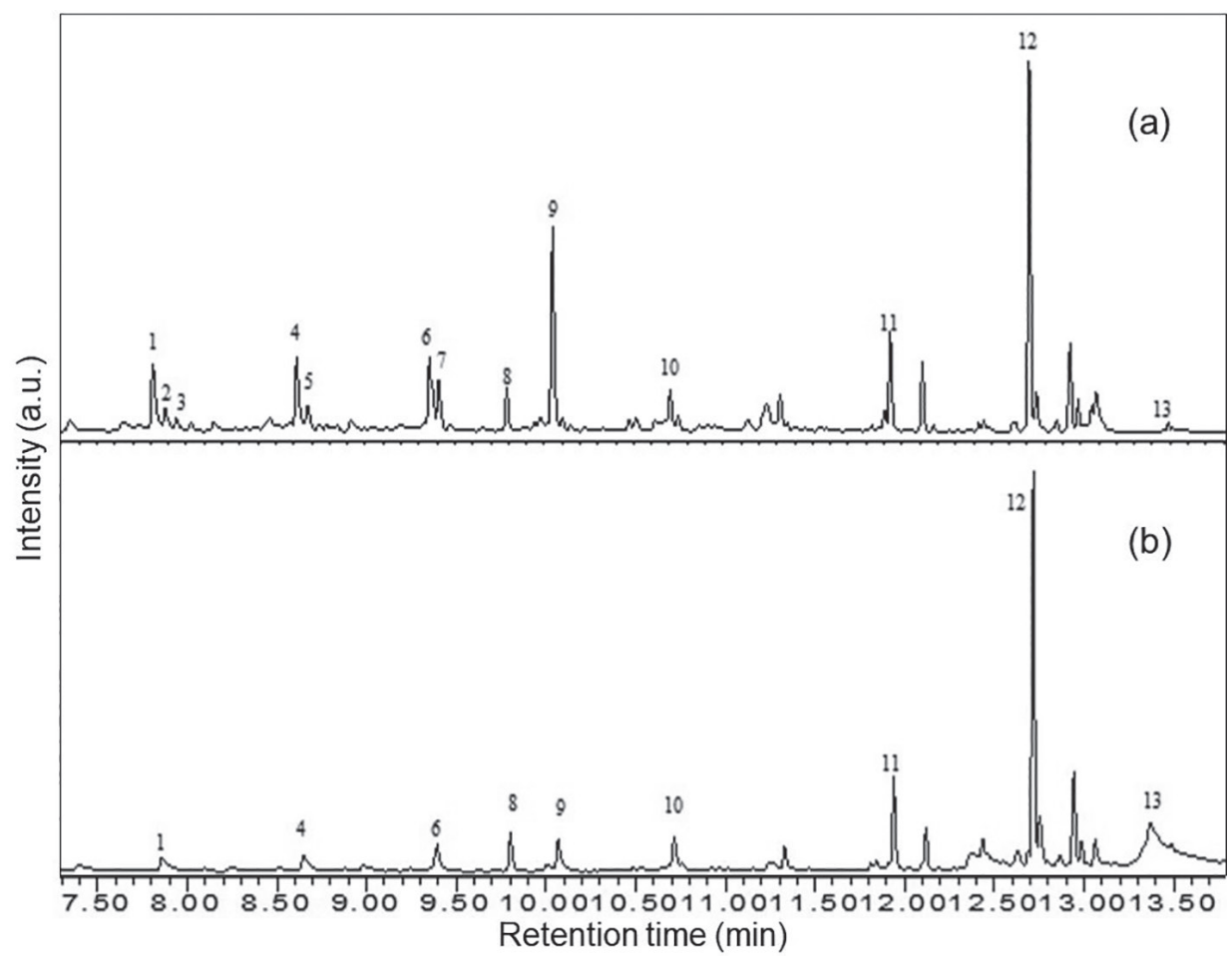

Figure 4. Comparison between the product profiles of the (a) catalyzed and (b) uncatalyzed fast pyrolysis of Desmodesmus sp. (n-hexane extract), at $600{ }^{\circ} \mathrm{C}$ : selected section of global pyrograms between retention times 7.3 to $13.8 \mathrm{~min}$. Compounds identified: (1) 1-undecene; (2) undecane; (3) 2-undecene; (4) 1-dodecene; (5) dodecane; (6) 1-tridecene; (7) tridecane; (8) cyclopentane 1,2-dibutyl; (9) 1-tetradecene; (10) 1-pentadecene; (11) heptadecane; (12) Z-2-octadecen-1-ol; (13) hexadecanoic acid.

are still very complex, and their pyrolysis increased this complexity, especially in the catalytic process.

Depending on the pyrolyzed extract and the solvent used, a range of 4 to $44 \%$ of the products were classified as not identified (NI) products when considering the complete pyrograms. Its high percentage is mainly associated with the low robustness of the analytical method used, considering the large number of compounds produced during pyrolysis, including isomers, and a limited separation quality. Moreover, the less volatile compounds found at higher retention times are difficult to identify. These compounds with high molecular weight are mostly oxygenated, such as cholesterol and fatty esters (mono, di, and/or tri-esters), and possibly traces of nitrogen compounds. The fraction of light compounds also could not be completely identified with the predefined quality (70\%), but they are probably $\mathrm{CO}_{2}, \mathrm{C} 2$ to $\mathrm{C} 4$ hydrocarbons and other possible light substances such as $\mathrm{NO}_{x}, \mathrm{~N}_{2}$ and/or $\mathrm{NH}_{3}$ having their elution in limited retention time interval. When pyrolyzing simple sodium salts of $\mathrm{C} 18$ fatty acids, Lappi and Alén ${ }^{52}$ showed that unidentified products can amount to $26 \%$ of the total pyrograms, with reagent feed much simpler than the ones used in the present work. However, the compounds not identified having a number of carbon atoms between 9 and 15 , the range considered for kerosene fraction, object of the present study, are in non-significant quantity. Furthermore,

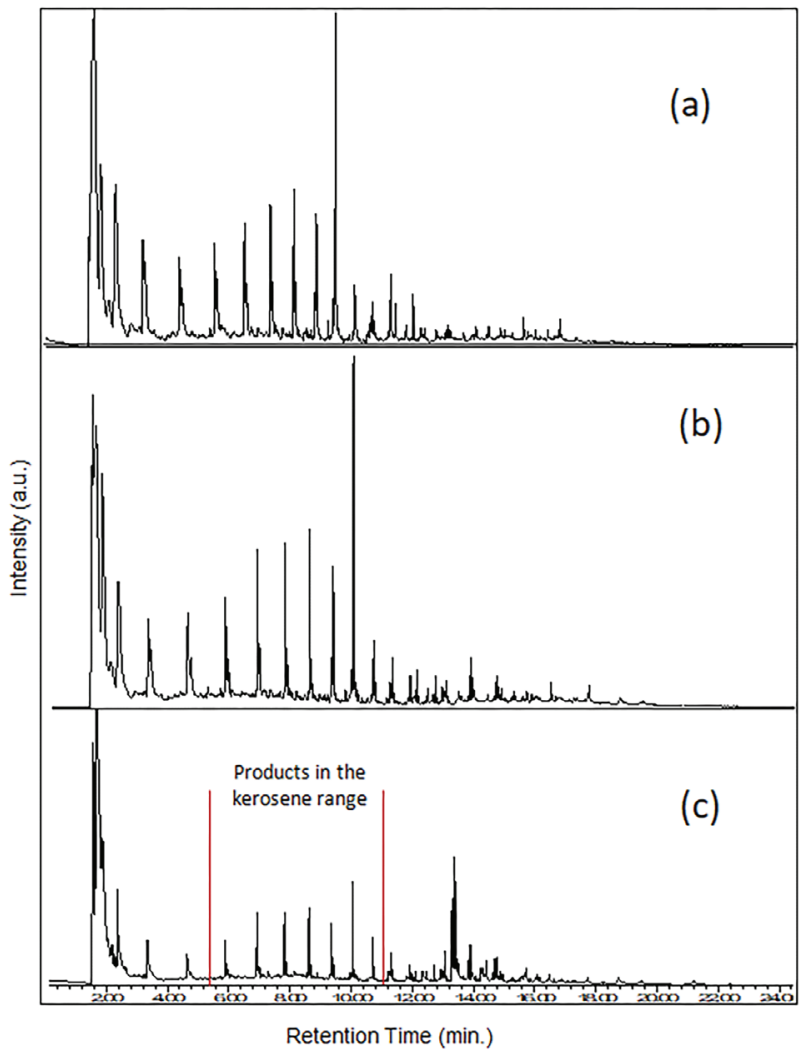

Figure 5. Fast pyrolysis at $600{ }^{\circ} \mathrm{C}$ of Nannochloropsis oculata extracts with the solvents: (a) hexane; (b) hexane + isopropanol and (c) chloroform + methanol, with $\gamma$-alumina as catalyst. 
among the products identified, no nitrogen compounds were identified, except with Halamphora coffeaeformis, for which pyrolysis led to less than $1 \%$ of such compounds. The low contents of nitrogen compounds suggest that the extraction, with hexane mainly, was selective enough to limit protein extraction, always present in quantity as large as 15 to $26 \%$, on a dry basis. ${ }^{42}$

The absence of nitrogenous substances in the C9-C15 fractions is extremely important to the use of microalgae pyrolysis products for biofuels purpose, as such compounds may deactivate refining catalysts and generate $\mathrm{NO}_{x}$, i.e., polluting species, during fuel combustion. Gautam and Vinu, ${ }^{53}$ performing non-catalytic and catalytic fast pyrolysis of Nannochloropsis oculata using $\mathrm{Co}-\mathrm{Mo} / \gamma-\mathrm{Al}_{2} \mathrm{O}_{3}$ catalyst, without any extraction, generated a lot of nitrogenous compounds and phenols, not very suitable for green fuel production.

As recalled above, the fine analysis of the pyrograms of microalgae extracts was limited to products having carbon atoms between 9 and 15, observed between retention times of 5.9 and $11.0 \mathrm{~min}$. Among the three microalgae species studied, Halamphora coffeaeformis was the one that presented the highest yield of $\mathrm{C} 9-\mathrm{C} 15$ products (78 to $86 \%$ ), before Nannochloropsis oculata (54 to $56 \%$ ) and Desmodesmus sp., (45 to 68\%). In complete pyrograms, formation of hydrocarbons from $\mathrm{C} 5$ to $\mathrm{C} 18$, and carboncarbon bonds similar to those existing in fuels such as liquefied petroleum gas (LPG), gasoline and light diesel were observed. The hydrocarbon profile was predominantly 1 -alkenes and alkanes with the same carbon number. Again, the influence of the solvent is noted: with increasing polarity, more substances were extracted, and the number and amount of pyrolysis products outside the range studied (C9-C15) increased, as shown in Figure 5.

Figure 6 shows the main pyrolysis products in the range C5-C18, highlighting the C9-C15 fraction, for extracts using solvents: (1) hexane, (2) hexane + isopropanol, (3) chloroform + methanol.

The number and content of products varied greatly depending on the microalgae species and solvent used. Hexane extracts of Halamphora coffeaeformis presented after catalytic pyrolysis more hydrocarbons in the kerosene range and less by-products when compared to all the other extracts and can be considered both the best raw feedstock and solvent to obtain bio-kerosene-like fraction under the present pyrolysis conditions. The other two solvents, with increasing polarity, despite giving higher mass yields of extract products led to, after pyrolysis, a greater content of by-products as a whole, for example in the diesel range, as shown in Figure 5c. Analyzing all the data obtained, these mixtures (hexane + isopropanol and chloroform +
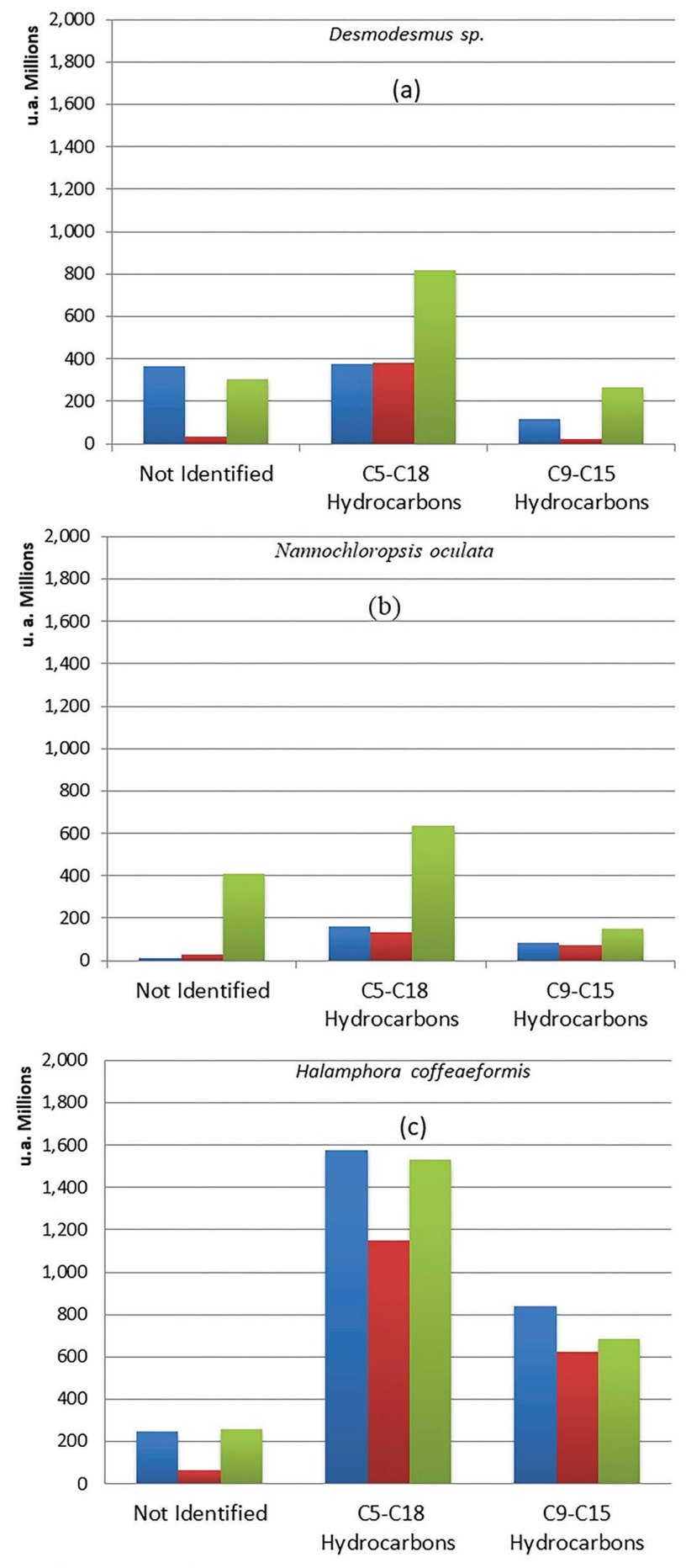

(1) Hexane

(2) Hexane + isopropanol

(3) Chloroform + methanol

Figure 6. Catalytic pyrolysis products of extracts: global hydrocarbon (C5-C18) and kerosene fraction (C9-C15), for (a) Desmodesmus sp.; (b) Nannochloropsis oculata and (c) Halamphora coffeaeformis species.

methanol) exhibited extract yields and/or quality lower than the ones exhibited by the $n$-hexane solvent alone, considering the $\mathrm{C} 9-\mathrm{C} 15$ hydrocarbon fraction.

Figure 7 presents the distribution of the main hydrocarbon fractions in the $\mathrm{C} 9-\mathrm{C} 15$ range obtained after 
catalytic pyrolysis of extracts from Desmodesmus sp. (Figure 7a) Nannochloropsis oculata (Figure 7b) and Halamphora coffeaeformis (Figure 7c) biomasses.

In this 9 to 15 carbon chain length range, $\mathrm{C} 14$ and $\mathrm{C} 12$ were present in greater amount, and unsaturated products like 1-alkenes were the most abundant. Saturated products
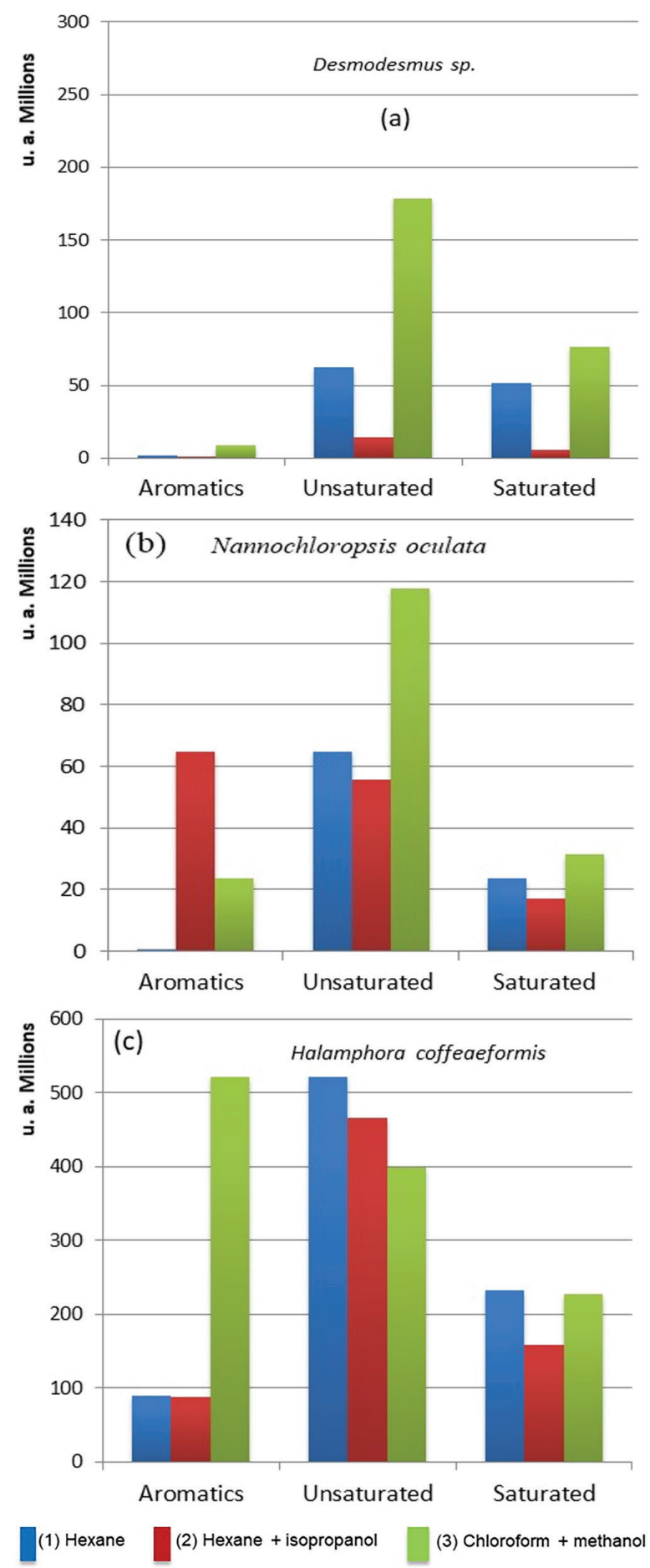

Figure 7. Saturated, unsaturated and aromatic hydrocarbons in the C9-C15 range, obtained by extracts catalytic pyrolysis of (a) Desmodesmus sp.; (b) Nannochloropsis oculata and (c) Halamphora coffeaeformis species. were essentially linear aliphatics, but some iso-paraffin and naphthenic fractions were also detected. Although undesirable in practical aviation kerosene, the linear hydrocarbons can readily be converted into iso alkanes for example in the presence of supported bifunctional metal catalysts. $^{54}$

The content of aromatics ranged from 1 to $10 \%$, the latter value being obtained with Halamphora coffeaeformis extracted with hexane, as shown in Figure 7c. In kerosene fuels, aromatics are needed to prevent freezing in all parts of the engine as well as to help lubrication. However, the presence of aromatics, potential carcinogenic products, induces the formation of soot. In fact, in kerosene, aromatics must have a maximum certified composition of 8\% (ASTM D7566) 55 and this content can be adjusted by catalytic processes ${ }^{56}$ The values obtained in the present study are not very far from the ASTM limits and small changes in the experimental pyrolysis conditions can probably lead to fully acceptable "drop in" kerosene.

\section{Conclusions}

The extraction of fatty compounds synthesized by three microalgae species, Nannochloropsis oculata, Halamphora coffeaeformis and Desmodesmus sp. was performed using $n$-hexane, a mixture of $n$-hexane-isopropanol and a mixture of methanol-chloroform. The amount of extract, whatever the microalgae, increased from 2 to $23 \mathrm{wt} . \%$ with increasing polarity of the solvent. Infrared spectra of the extracts did not allow to differentiate in a detailed way the composition of the extracts. However, the use of micro pyrolysis performed at $600{ }^{\circ} \mathrm{C}$ revealed differences in the composition of the extracts, and consequently of the starting microalgae biomass. In the whole pyrograms, deoxygenated products varied between 46 and $92 \%$.

The best case was pyrolysis of Halamphora coffeaeformis $n$-hexane extract catalyzed by $\gamma$-alumina, giving very high selectivity for C5-C18 hydrocarbons, being suitable for green fuels production. The $\mathrm{C} 9-\mathrm{C} 15$ fraction of these hydrocarbons was object of detailed analysis. In this fraction, nitrogenous products had concentrations always lower than $0.1 \%$. The main hydrocarbons produced were 1-alkenes for thermal pyrolysis whereas for pyrolysis with $\gamma$-alumina, 1 -alkenes, linear alkanes and alkenes isomers, together with cyclic and aromatic products were observed for all microalgae species, but in different proportions. The low contents of nitrogen compounds suggest that the extraction, with hexane mainly, was selective enough to limit protein extraction. The $\mathrm{C} 9-\mathrm{C} 15$ fraction of pyrolyzed extracts can be considered as precursor for biokerosene or direct "drop in" fuel for kerosene petroleum fraction. 


\section{Acknowledgments}

This paper was prepared with the support of the Bahia State Research Support Foundation (FAPESB), Higher Education Personnel Improvement Coordination (CAPES) and the National Council for Scientific and Technological Development (CNPq), Brazil. Furthermore, the authors are grateful to Alcoa Company for the supply of alumina sample, to the Coordination Chemistry Research Group (GPQC) for their assistance in FTIR analysis and to the Catalysis and Environment Group (CATAM) for their assistance in thermal analysis, both from the Federal University of Bahia (UFBA).

\section{References}

1. Suali, E.; Sarbatly, R.; Renewable Sustainable Energy Rev. 2012, 16, 4316.

2. Nguyen, M. K.; Moon, J.-Y.; Bui, V. K. H.; Oh, Y.-K.; Lee, Y.-C.; Algal Res. 2019, 41, 101522.

3. Fan, L.; Zhang, H.; Li, J.; Wang, Y.; Zhou, W.; Algal Res. 2020 , 47, 101819.

4. Maher, K. D.; Bressler, D. C.; Bioresour. Technol. 2007, 98, 2351.

5. Santos, M.; Arias, S.; Padilha, J.; Carneiro, M. C.; Sales, E. A.; Pacheco, J. G.; Fréty, R.; Catal. Today 2020, 344, 234.

6. Manara, P.; Bezergianni, S.; Pfisterer, U.; Energy Convers. Manage. 2018, 165, 304.

7. Fogassy, G.; Thegarid, N.; Toussaint, G.; Veen, A.; Schuurman, Y.; Mirodatos, C.; Appl. Catal., B 2010, 96, 476.

8. Quintella, C.; Teixeira, L.; Korn, M.; Costa Neto, P.; Torres, E.; Castro, M.; Jesus, C.; Quim. Nova 2009, 32, 793.

9. Gegg, P.; Ison, S.; J. Air Transp. Manage. 2014, 39, 34.

10. Bondioli, P.; Bella, L.; Rivolta, G.; Zittell, G.; Bassi, N.; Rodolf, L.; Casini, D.; Prussi, M.; Chiaramonti, D.; Tredici, M.; Bioresour. Technol. 2012, 114, 567.

11. Sánchez-Silva, L.; Lopez-Gonzalez, D.; García-Minguillán, A.; Bioresour. Technol. 2013, 130, 321.

12. Prado, G.; Rao, Y.; Klerk, A.; Energy Fuels 2017, 31, 14.

13. Bach, Q.; Chen, H.; Bioresour. Technol. 2017, 246, 88.

14. Choo, M.; Oi, L.; Show, P.; Chang, J.; Ling, T.; Ng, E.; Phang, S.; Juan, J.; J. Taiwan Inst. Chem. Eng. 2017, 79, 116.

15. Li, F.; Srivatsa, S.; Bhattacharya, S.; Renewable Sustainable Energy Rev. 2019, 108, 481.

16. Maguyon, M.; Capareda, S.; Energy Convers. Manage. 2013, 76, 764.

17. Gong, X.; Zhang, B.; Zhang, Y.; Huang, Y.; Xu, M.; Energy Fuels 2014, 28, 95.

18. Silva, F.; Monteggia, L.; Front. Energy Res. 2015, 3, 31.

19. Gang, L.; Dong, R.-j.; Fu, N.; Zhou, Y.-G.; Li, D.; Chen, X. D.; Int. J. Food Eng. 2015, 11, 825.
20. Gang, L.; Shunan, X.; Fang, J.; Yuguang, Z.; Mengmeng, J.; Zhigang, H.; Int. J. Agric. Biol. Eng. 2017, 10, 218.

21. Gang, L.; Shunan, X.; Fang, J.; Yuguang, Z.; Zhigang, H.; Int. J. Agric. Biol. Eng. 2017, 10, 198.

22. Pinho, A. R.; de Almeida, M. B. B.; Mendes, F. L.; Casavechia, L. C.; Talmadge, M. S.; Kinchin, C. M.; Chum, H. L.; Fuel 2017, 188, 462.

23. Wang, H.; Lin, H.; Zheng, Y.; Ng, S.; Brown, H.; Xia, Y.; Catal. Today 2019, 319, 164.

24. Thangalazhy-Gopakumar, S.; Adhikari, S.; Chattanathan, S.; Gupta, R.; Bioresour. Technol. 2012, 118, 150.

25. Torri, C.; Fabbri, D.; Garcia-Alba, L.; Brilman, D.; J. Anal. Appl. Pyrolysis 2013, 101, 28.

26. Wang, K.; Brown, R.; Green Chem. 2013, 15, 675.

27. Du, D.; Ma, X.; Li, Y.; Chen, P.; Liu, Y.; Lin, X.; Lei, H.; Ruan, R.; Bioresour. Technol. 2013, 139, 397.

28. Aysu, T.; Sanna, A.; Bioresour. Technol. 2015, 194, 108.

29. Conti, R.; Fabbri, D.; Vassura, I.; Ferroni, L.; J. Anal. Appl. Pyrolysis 2016, 122, 160.

30. Anand, V.; Gautam, R.; Vinu, R.; Fuel 2017, 205, 1.

31. Ren, R.; Han, X.; Zhang, H.; Lin, H.; Zhao, J.; Zheng, Y.; Wang, H.; Carbon Resour. Convers. 2018, 1, 153.

32. Chang, G.; Miao, P.; Wang, H.; Wang, L.; Hu, X.; Guo, Q.; Energy Convers. Manage. 2018, 173, 545.

33. Zainan, N.; Srivatsa, C.; Li, F.; Bhattacharya, S.; Fuel 2018, $223,12$.

34. Shimada, I.; Nakamura, Y.; Kato, S.; Mori, R.; Ohta, H.; Suzuki, K.; Takatsuka, T.; Biomass Bioenergy 2018, 112, 138.

35. Fréty, R.; da Rocha, M. G. C.; Brandão, S. T.; Pontes, L. A. M.; Padilha, J. F.; Borges, L. E. P.; Gonzalez, W. A.; J. Braz. Chem. Soc. 2011, 22, 1206.

36. Cruz, Y.; Díaz, G.; Borges, V.; Leonett, A.; Carliz, R.; Rossa, R.; Silva, V.; Viegas, C.; Aranda, D.; Oliveira, L.; J. Power Energy Eng. 2019, 7, 80.

37. Sander, K.; Murthy, G.; Int. J. Life Cycle Assess. 2010, 5, 704.

38. Leung, A.; Boocock, D.; Konar, S.; Energy Fuels 1995, 9, 913.

39. Vonghia, E.; Boocock, D.; Konar, S.; Leung, A.; Energy Fuels 1995, 9, 1090.

40. Dos Anjos, J. R.; Gonzalez, W.; Lam, Y.; Fréty, R.; Appl. Catal. 1983, 5, 299.

41. Billaud, F.; Guitard, Y.; Minh, A.; Zahraa, O.; Lozano, P.; J. Mol. Catal. A: Chem. 2003, 192, 281.

42. Lourenço, S.; Campos, V.; Barbarino, E.; Cienc. Rural 2009, 40, 339 .

43. Stein, S.; Handbook of Phycological Methods. Culture Methods and Growth Measurements; Cambridge University Press: London, 1980.

44. Chen, C.; Ma, X.; Liu, K.; Appl. Energy 2011, 88, 3189.

45. Agrawal, A.; Chakraborty, S.; Bioresour. Technol. 2013, 128, 72. 
46. Fahmi, R.; Bridgwater, A.; Darvel, L.; Jones, J.; Yates, N.; Thain, S.; Donnison, I.; Fuel 2007, 86, 1560.

47. Xu, Q.; Ma, X.; Yu, Z.; Cai, Z.; Appl. Therm. Eng. 2014, 73, 357.

48. Stepan, E.; Enascuta, C.; Oprescu, E.; Radu, E.; Radu, A.; Galan, A. M.; Vasilievici, G.; Lavric, V.; Velea, S.; Fuel 2016, 172, 29.

49. Pines, H.; Haag, W.; J. Am. Chem. Soc. 1961, 83, 2847.

50. Shimada, I.; Kato, S.; Hirazawa, N.; Nakamura, Y.; Ohta, H.; Suzuki, K.; Takatsuka, T.; Ind. Eng. Chem. Res. 2017, 56, 75.

51. Renz, M.; Eur. J. Org. Chem. 2005, 6, 979.

52. Lappi, H.; Alén, R.; J. Anal. Appl. Pyrolysis 2011, 91, 154.
53. Gautam, R.; Vinu, R.; Algal Res. 2018, 34, 12.

54. Dhar, A.; Vekariya, R.; Bhadja, P.; Cogent Chem. 2018, 4, 1514686

55. ASTM D7566-20b: Standard Specification for Aviation Turbine Fuel Containing Synthesized Hydrocarbons; ASTM International: West Conshohocken, PA, USA, 2020.

56. Simão, B.; Júnior, J. S.; Chagas, B.; Cardoso, C.; Ataíde, C.; Algal Res. 2018, 32, 221.

Submitted: August 20, 2020

Published online: November 24, 2020 